\title{
Creating a common terminology for play behavior to increase cross-disciplinary research
}

\author{
Lance J. Miller ${ }^{1}$
}

Published online: 12 July 2017

(C) Psychonomic Society, Inc. 2017

\begin{abstract}
Historically, play behavior has been difficult to define. This likely stems from the number of different species, types of play, and context under which it occurs. In 2016, the Chicago Zoological Society - Brookfield Zoo hosted the Psychonomic Society leading edge workshop on the evolutionary and psychological significance of play. Sixteen experts attended from the diverse fields of African ethnology, animal behavior, animal science, animal welfare, cognitive psychology, cognitive zoology, comparative psychology, cultural anthropology, developmental psychology, educational psychology, ethology, neuroscience, primatology, and zoology. Approximately half of the participants studied human play and the other half studied non-human play. Before the workshop, participants were asked to send in either their personal definition of play or the one that they cite in peer-reviewed literature. Definitions were then reviewed to determine characteristics of play inclusive of all disciplines. The goal of the current study was not to do a literature review on play behavior, but to come up with a list of characteristics across all forms of play that could be used as a common terminology moving forward. Hopefully the results of this workshop and the current article will help to increase cross-disciplinary research in the field of play.
\end{abstract}

Keywords Animal $\cdot$ Behavior · Common language ·

Evolutionary benefit $\cdot$ Human $\cdot$ Play

Lance J. Miller

Lance.Miller@CZS.org

1 Chicago Zoological Society - Brookfield Zoo, 3300 Golf Road, Brookfield, IL 60513, USA
Play has been documented in a diversity of species across many different taxonomic groups. These include a variety of mammals (e.g., Cordoni \& Palagi, 2016; Kuczaj \& Eskelinen, 2014; Pellis \& Iwaniuk, 2000), birds (e.g., Auersperg et al., 2015; Osvath, Osvath \& Baath, 2014), reptiles (e.g., Barabanov et al., 2015; Dinets, 2015), amphibians (e.g., Burghardt, 2015), fish (e.g., Burghardt, Dinets, \& Murphy, 2015), and invertebrates (e.g., Kuba, Gutnick, \& Burghardt 2014; Zylinski, 2015). However, although a diversity of species play, all play is not the same. This creates the challenge of defining play behavior as it can vary so drastically from one species to the next. For example, object play by an octopus (Kuba, Gutnick, \& Burghardt, 2014) is quite different in form and likely function compared to playing with imaginary friends in children (Gleason, 2013). With such a great diversity of species, types of play, and disciplines involved in the study of the behavior, it is no surprise that play behavior is difficult to define.

In general, behavior can be defined based on function or structure (Burghardt, 2005). Definitions based on function rely on descriptions of the end result of the behavior. Definitions based on structure help to define how the behavior looks. Depending on the field of study (e.g., neuroscience, psychology, anthropology), definitions could look quite different, especially with the many different forms of play. This is evidenced by some initial attempts by Fagan (1981) to explore definitions of play. A more recent approach to defining play was a set of five criteria that must be met to be characterized as play (Burghardt 2005).

"The first criterion for recognizing play is that the performance of the behavior is not fully functional in the form or context in which it is expressed; that is, it includes elements, or is directed toward stimuli, that do not contribute to current survival. 
The second criterion for recognizing play is that the behavior is spontaneous, voluntary, intentional, pleasurable, rewarding, reinforcing, or autotelic ('done for its own sake').

The third criterion for recognizing play is that it differs from the 'serious' performance of ethotypic behavior structurally or temporally in at least one respect: it is incomplete (generally through inhibited or dropped final elements), exaggerated, awkward, or precocious; or it involves behavior patterns with modified form, sequencing, or targeting.

The fourth criterion for recognizing play is that the behavior is performed repeatedly in a similar, but not rigidly stereotyped, form during at least a portion of the animal's ontogeny.

The fifth criterion for recognizing play is that the behavior is initiated when an animal is adequately fed, healthy, and free from stress (e.g., predator threat, harsh microclimate, social instability), or intense competing systems (e.g., feeding, mating, predator avoidance). In other words, the animal is in a 'relaxed field'."

However, the fifth criterion has been questioned with regard to human play (Lillard, 2014). The same author has also stated that the criteria created by Burghardt (2005) are likely one of the most useful to date (Lillard, 2014). What is clear from previous attempts is that having a definition of play across species, types of play, and context is quite challenging.

As stated previously, there are many disciplines examining play behavior, which results in many different definitions of play. However, a common terminology across all disciplines could help encourage cross-disciplinary research, which has helped move research forward in the past (e.g., Century et al., 2012). Other related and unrelated fields have also found having a common terminology important in order to facilitate high-quality research (e.g., General Psychology: Edmonds \& Kennedy, 2016; Software Measurement: Garcia et al., 2006; Species Diversity: Jurasinski et al., 2009; Animal Behavior: Kalueff et al., 2013). It is possible that having a common terminology or language across all disciplines that study play can help move the field forward to understanding this complex behavior.

The goal of the current study is to not provide a review of the play literature as there are already many good reviews currently available in different scientific disciplines (e.g., Burghardt 2005; Lillard 2014; Muir, Munroe-Chandler, \& Guerrero, 2016). Rather the goal of the current study is to identify characteristics of play behavior across species, type, and context that can be used as a common terminology or language in the field of play. In 2016, the Chicago Zoological Society - Brookfield Zoo held a workshop on the evolutionary and psychological significance of play. During the workshop, 16 experts were asked to give their definition of play or the one cited in peer-reviewed manuscripts. The definitions can help advance the research of play by ensuring all characteristics of play are accounted for when thinking about or discussing play. The goal is not to define play but to list the characteristics of play across all disciplines involved in the workshop. This will allow for a common language across all fields of research on play given the large number of disciplines involved in this complex topic. Hopefully in the end this will move the field of play forward to better understand the evolutionary and psychological significance of play.

\section{Methods}

The 2016 Psychonomic Society Leading Edge Workshop on the Evolutionary and Psychological Significance of Play was held at the Chicago Zoological Society - Brookfield Zoo from 12-14 June 2016. The participants who attended the workshop were selected on the basis of having a broad diversity of backgrounds within the field of play. Their backgrounds included the fields of African ethnology, animal behavior, animal science, animal welfare, cognitive psychology, cognitive zoology, comparative psychology, cultural anthropology, developmental psychology, educational psychology, ethology, neuroscience, primatology, and zoology. Approximately half of the participants studied human play and the other half studied non-human play. Before the workshop started, participants were asked to submit either their definition of play or the definition that they cite in peer-reviewed manuscripts. Definitions were then examined to determine central themes or characteristics of play. Responses were then examined to determine the number of definitions that contained each characteristic as well as the total number of characteristics that fell into each type of definition (structural vs. functional). A chisquare test of significance was used to examine differences in structural versus functional definitions and a Wilcoxon test was used to examine differences between human and nonhuman definitions. For all statistical tests, the alpha level was set at $\mathrm{p}<0.05$.

\section{Results}

The most common submission was a personal definition $(62.5 \%)$ that included no reference or citation. The most common cited definition of play ( $25 \%$ ) was the criteria developed by Burghardt (2005) followed by Rubin, Fein, and Vandenberg (1983) and Lillard (2014), 6.3\% for each definition. Overall, there were 17 different characteristics of play identified throughout the 16 definitions. These characteristics of play included the following. 


\section{Structural characteristics}

1. Intrinsic - Play happens for intrinsic reasons, there is no external reward, and it is internally motivated.

2. Young Individuals - Play is more likely to occur in young individuals than older individuals and the function may vary depending on age.

3. Voluntary - Play is voluntary and an individual must intentionally and knowingly choose to participate in the behavior.

4. Repetitive - Play is repetitive in nature, lacking inhibition, but the behavior is not stereotyped.

5. Spontaneous - Play is spontaneous and comes with some flexibility that can be in the form of process, objects utilized, or the actor.

6. Positive Welfare - Play occurs when an individual is in a positive state of health and welfare.

7. Fragmented - Play is fragmented or incomplete and is modified from typical behavioral patterns with immediate function.

8. Exaggerated - Play is exaggerated or awkward compared to typical behavior with immediate function.

9. Play Signals - Play is accompanied by speciesdependent play signals either before or during the behavior.

10. Turn Taking - Play involves turn-taking where individuals take turns in different roles.

11. Non-literal - Play is non-literal or imaginative requiring mental representations that are mapped onto some reality.

12. Process Orientated - Play is process orientated based on a set of rules.

\section{Functional characteristics}

1. Rewarding - Play is rewarding or pleasurable for the individual engaged in the behavior and leads to positive emotions such as joy or enjoyment.

2. No Immediate Benefit - From an evolutionary perspective, play behavior has no obvious immediate benefits leading to an individual's current survival.

3. Contextual - Play may have different functions depending on the context under which they occur.

4. Social Facilitation - Play facilitates social interaction and is contagious among peers or conspecifics.

5. Evolutionary Benefit - There are evolutionary benefits to play.

Examining all the characteristics across definitions there were 12 based on structure and five based on function of the play behavior $\left(\chi^{2}=2.88 ; \mathrm{p}=\mathrm{n}\right.$.s.). Table 1 displays the terms including the number of times each was included in
Table 1 Number of definitions that contained each of the play characteristics and type

\begin{tabular}{lllll}
\hline Characteristic & Overall & Human & Non-human & Type \\
\hline Rewarding & 11 & 4 & 7 & $\mathrm{~F}$ \\
Intrinsic & 8 & 2 & 6 & $\mathrm{~S}$ \\
Young individuals & 8 & 3 & 5 & $\mathrm{~S}$ \\
No immediate benefits & 8 & 2 & 6 & $\mathrm{~F}$ \\
Voluntary & 7 & 3 & 4 & $\mathrm{~S}$ \\
Repetitive & 7 & 1 & 6 & $\mathrm{~S}$ \\
Spontaneous & 6 & 0 & 6 & $\mathrm{~S}$ \\
Positive welfare & 6 & 0 & 6 & $\mathrm{~S}$ \\
Fragmented & 5 & 0 & 5 & $\mathrm{~S}$ \\
Exaggerated & 5 & 0 & 5 & $\mathrm{~S}$ \\
Play signals & 5 & 1 & 4 & $\mathrm{~S}$ \\
Turn-taking & 3 & 1 & 2 & $\mathrm{~S}$ \\
Non-literal & 3 & 3 & 0 & $\mathrm{~S}$ \\
Contextual & 3 & 1 & 2 & $\mathrm{~F}$ \\
Socially contagious & 3 & 1 & 2 & $\mathrm{~F}$ \\
Process orientated & 2 & 2 & 0 & $\mathrm{~S}$ \\
Evolutionary benefits & 2 & 1 & 1 & $\mathrm{~F}$ \\
\hline
\end{tabular}

$F$ functional, $S$ structural

definitions for human and non-human play. Scientists who primarily study human play behavior used significantly less characteristics in their definitions than their non-human play counterparts $(z=2.83 ; p<0.01)$. There were four different characteristics that were never utilized by human play scientists while only two characteristics were not utilized by nonhuman play scientists. The most common characteristic was that play is rewarding or positive in nature $(n=11)$, while the least common characteristics were that play leads to evolutionary benefits $(n=2)$ and is process orientated $(n=2)$.

\section{Discussion}

The resulting 17 characteristics of play further emphasize the complexity of the behavior and its study. As previously stated, although a broad diversity of species play, all play is not the same. It is not surprising that many of the characteristics of play are quite similar to the criteria proposed by Burghardt (2005) given the number of participants who submitted this definition and what are considered to be the best criteria for determining play (Lillard, 2014). However, the current list of characteristics generated from 16 experts across a diversity of backgrounds can hopefully serve as a common language or terminology across all disciplines of play research. From anthropology to zoology, there are many fields that could benefit from such a list to ensure everyone is talking the same language. In addition, hopefully having a common terminology 
will increase cross-disciplinary work to move the field forward.

While not significantly different, it is clear the majority of the participants use definitions that are based on structure as opposed to function. This is not surprising given the lack of scientific evidence to date demonstrating the long-term evolutionary benefits of play. While there are many theories (e.g., motor skills, cognitive development), research is still needed to understand the likely many functions of play. Generating a list of characteristics of play based on structure is much simpler as one can simply describe the observed behavior. The characteristics of repetitiveness, exaggeration, and awkwardness are all good examples of how the behavior may appear (Burghardt, 2005). However, the most common characteristic that occurred across definitions was based on function. Play is fun or rewarding and leads to a state of positive emotions (Burghardt, 2005; Lillard, 2014; Rubin, Fein, \& Vandenberg, 1983). While easy to survey human participants regarding emotional state, this is much more difficult with non-human subjects. However, with the increased work surrounding cognitive bias testing, questions regarding positive emotions and play in non-human animals is now quite possible (Harding, Paul, \& Mendl, 2004; Mendle, Burman, Parker, $\&$ Paul, 2009).

It is important to note that some of the characteristics will never be applicable to some types of play behavior. For example, an individual human or non-human animal can play in the form of either social play (two or more individuals) or solitary play. Solitary play would obviously not allow for turn-taking, which is one of the characteristics often seen in both human and non-human animal play (Pellis \& Pellis, 2012). Another example, in relation to imaginative play, is we currently do not have a good understanding of the sentience of some taxonomic groups and if that type of play behavior would even be possible (Proctor, 2012). However, using a common terminology moving forward will hopefully allow for a better understanding of the different types of play behavior seen across different taxonomic groups.

One difference that does exist between the human and nonhuman play research communities is the complexity of the definitions. A good example is Burghardt's (2005) five criteria of play, which give really good structural definitions of play in animals. In general, it appears from this limited sample size that non-human animal definitions are more complex than their human play research counterparts. However, the characteristics that were not present in the human and non-human definitions were all structural in definition, suggesting that there might be contextual differences in the appearance of play. Given the vast number of species represented by the group of experts, it is not surprising that play might look different.

While the goal of the current study was not to define play or to conduct a thorough review of the literature on play, it was the goal to review definitions used across many diverse disciplines to see the similarities and differences and come up with a list of characteristics of play that would be inclusive of all disciplines. While all characteristics might not be relevant to all disciplines, all disciplines are hopefully represented in the list. Future work could aid the current work in expanding the sample size as the current list might not be exhaustive given the limited number of participants. Hopefully it is a good start to creating a common terminology that can be used across disciplines to continue to move the field forward. In the end, if this workshop increases cross-discipline collaboration within the field of play, then the goal will have been accomplished.

Acknowledgements I would like to thank all of the participants of the 2016 Psychonomic Society Workshop held at the Chicago Zoological Society - Brookfield Zoo. This includes Alex de Voogt, Cindy Dell Clark, Vladimir Dinets, Tracy Gleason, Fernand Gobet, Artin Göncü, Martine Hausberger, Heather Hill, Angeline Lillard, Mathias Osvath, Elisabetta Palagi, Jaak Panksepp, Sergio Pellis, Jeff Rushen, and Marek Spinka. I would also like to thank the Psychonomic Society for funding the workshop and Louis Shomette for all his assistance. Finally, I would like to thank Stan Kuczaj (1951-2016) for making the workshop possible. $\mathrm{He}$ will be forever missed and his dedication to the field will never be forgotten.

\section{References}

Auersperg, A. M., van Horik, J. O., Bugnyar, T., Kacelnik, A., Emery, N. J., \& von Bayern, A. M. (2015). Combinatory actions during object play in psittaciformes (Diopsittaca nobilis, Pionites melanocephala, Cacatua goffini) and corvids (Corvus corax, C. monedula, C. moneduloides). Journal of Comparative Psychology, 129(1), 62.

Barabanov, V., Gulimova, V., Berdiev, R., \& Saveliev, S. (2015). Object play in thick-toed geckos during a space experiment. Journal of Ethology, 33(2), 109-115.

Burghardt, G. M. (2005). The genesis of animal play: Testing the limits. Mit Press.

Burghardt, G. M. (2015). Play in fishes, frogs and reptiles. Current Biology, 25(1), R9-R10.

Burghardt, G. M., Dinets, V., \& Murphy, J. B. (2015). Highly repetitive object play in a cichlid fish (Tropheus duboisi). Ethology, 121(1), 38-44.

Century, J., Cassata, A., Rudnick, M., \& Freeman, C. (2012). Measuring enactment of innovations and the factors that affect implementation and sustainability: Moving toward common language and shared conceptual understanding. The Journal of Behavioral Health Services \& Research, 39(4), 343-361.

Cordoni, G., \& Palagi, E. (2016). Aggression and hierarchical steepness inhibit social play in adult wolves. Behaviour, 153(6-7), 749-766.

Dinets, V. (2015). Play behavior in crocodilians. Animal Behavior and Cognition, 2(1), 49-55.

Edmonds, W. A., \& Kennedy, T. D. (2016). An Applied Guide to Research Designs: Quantitative, Qualitative, and Mixed Methods. Sage Publications.

Fagan, R. (1981). Animal play behavior. Oxford: Oxford University Press

García, F., Bertoa, M. F., Calero, C., Vallecillo, A., Ruíz, F., Piattini, M., \& Genero, M. (2006). Towards a consistent terminology for software measurement. Information and Software Technology, 48(8), $631-644$. 
Gleason, T. R. (2013). Imaginary Relationships 17. The oxford handbook of the development of imagination, 251.

Harding, E. J., Paul, E. S., \& Mendl, M. (2004). Animal behaviour: Cognitive bias and affective state. Nature, 427(6972), 312.

Jurasinski, G., Retzer, V., \& Beierkuhnlein, C. (2009). Inventory, differentiation, and proportional diversity: A consistent terminology for quantifying species diversity. Oecologia, 159(1), $15-26$.

Kalueff, A. V., Gebhardt, M., Stewart, A. M., Cachat, J. M., Brimmer, M., Chawla, J. S., .. \& \& Gaikwad, S. (2013). Towards a comprehensive catalog of zebrafish behavior 1.0 and beyond. Zebrafish, 10(1), 70 86.

Kuba, M. J., Gutnick, T., \& Burghardt, G. M. (2014). Learning from play in octopus. Cephalopod cognition, 57.

Kuczaj, S. A., \& Eskelinen, H. C. (2014). Why do dolphins play? Animal Behavior and Cognition, 1(2), 113-127.

Lillard, A. S. (2014). The development of play. In L. S. Liben, U. Müller, R. M. Lerner, L. S. Liben, U. Müller, \& R. M. Lerner (Eds.), Handbook of child psychology and developmental science: Cognitive processes (7th ed, Vol. 2, pp. 425-468). Hoboken: Wiley.
Mendl, M., Burman, O. H., Parker, R. M., \& Paul, E. S. (2009). Cognitive bias as an indicator of animal emotion and welfare: Emerging evidence and underlying mechanisms. Applied Animal Behaviour Science, 118(3), 161-181.

Muir, I., Munroe-Chandler, K., \& Guerrero, M. (2016). A literature review of children's active play. Journal of Exercise, Movement, and Sport, 48(1), 203.

Osvath, M., Osvath, H., \& Bååth, R. (2014). An exploration of play behaviors in raven nestlings. Animal Behavior and Cognition, 1(2), 157-165.

Pellis, S. M., \& Iwaniuk, A. N. (2000). Adult-adult play in primates: Comparative analyses of its origin, distribution and evolution. Ethology, 106(12), 1083-1104.

Pellis, S. M., \& Pellis, V. C. (2012). Play-fighting during early childhood and its role in preventing later chronic aggression. Encyclopedia on Early Childhood Development, 2012, 1-4.

Proctor, H. (2012). Animal sentience: Where are we and where are we heading? Animals, 2(4), 628-639.

Rubin, K. H., Fein, G. G., \& Vandenberg, B. (1983). Play. Handbook of Child Psychology, 4, 693-774.

Zylinski, S. (2015). Fun and play in invertebrates. Current Biology, 25(1), R10-R12. 